\title{
Desperate larvae: influence of deferred costs and habitat requirements on habitat selection
}

\author{
Che Elkin ${ }^{1}$, Dustin J. Marshall ${ }^{2, *}$ \\ ${ }^{1}$ Ecology Centre/School of Integrative Biology, and ${ }^{2}$ School of Integrative Biology/Centre for Marine Studies, \\ The University of Queensland, Queensland 4072, Australia
}

\begin{abstract}
As marine invertebrate larvae age, some accept a wider variety of settlement cues. A conceptual argument, the desperate larva hypothesis, has been proposed to explain this change in behaviour, and focuses on the idea that larvae should accept less preferred habitats as time goes by because the deferred costs of continued searching are too great. Whilst this model has explained why some species change their preferences as they age, it struggles to account for other species that do not. General theoretical considerations of the issue have tended to focus on a parameter space outside that which is likely to be typical of marine larvae. We adapted a more general dispersal/search model specifically for marine larvae and examined the influence of larval energy intake, planktonic mortality and habitat quality and abundance on the benefits of decreased selectivity at settlement. We found that decreased selectivity carries an adaptive benefit across the majority of our parameter space. Whenever planktonic mortality is high, larvae deplete their resources quickly (as is the case for most lecithotrophs) or there is little difference in the quality of different habitats (as for generalists); therefore, larvae should become less choosy with regards to settlement. However, our model suggests that decreasing selectivity will not be adaptive when larvae can feed or when there are large differences in the quality of potential habitats. Initial indications from the literature generally conform to the predictions of our model and the occurrence of decreasing selectivity can be predicted based on an organism's habitat specificity and ability to feed during the facultative planktonic stage. Our model predicts that habitat selection behaviour should also vary within species. For non-feeding larvae, larger larvae (i.e. those with more resources) should remain selective for longer than smaller larvae. For feeding larvae, local food availability in the plankton should strongly affect the benefits of delaying metamorphosis in the absence of settlement cues.
\end{abstract}

KEY WORDS: Settlement behavior · Carry-over effects

Resale or republication not permitted without written consent of the publisher

\section{INTRODUCTION}

Marine benthic invertebrates are often restricted to discrete habitat patches that vary in quality. Most species have a larval stage that disperses in search of new habitat, and selection is expected to favour habitat choices that maximize individuals' post-metamorphic performance. Consequently, species from a wide variety of taxa have evolved to colonize good quality habitats preferentially over poor quality habitats (Keough \& Downes 1982, Walters et al. 1999) and in many instances will continue searching or delay colonization in the absence of good habitat (Pechenik
1990). However, despite the benefits of selecting good quality habitats, there can be a high level of variability in the quality of habitats that searching individuals of the same species will accept (Raimondi \& Keough 1990). Given this variability, the question as to what ecological and evolutionary factors lead some individuals to accept sub-optimal habitat and others to reject it remains.

Dispersal in marine invertebrates has at least 2 phases: an obligate and a facultative phase. The obligate phase can last from a few hours to weeks and can include development into a larval form that is capable of settlement (i.e. is competent to metamorphose) and 
feeding in the plankton that continues until sufficient resources have been acquired. Whilst many factors such as temperature and larval food availability can affect the length of the obligate phase (Hentschel \& Emlet 2000), our primary focus here is on what affects the length of the facultative dispersal phase-when larvae are competent to settle and begin to encounter potential habitats.

For over $50 \mathrm{yr}$ it has been recognized that, in some species of marine invertebrate, young larvae require specific habitat cues in order to settle (Wilson 1953). However, as larvae age these requirements can become less stringent and older larvae can settle indiscriminately on any available surface or in response to a wider suite of cues, a process we will call 'decreasing selectivity' (Knight-Jones 1951, 1953, Rumrill 1989, Gibson 1994). For marine invertebrate larvae, mortality in the plankton (a direct cost of searching) can be extremely high (Morgan 1995), and delaying metamorphosis can deplete energetic reserves (a deferred cost of searching) that could otherwise be used for post-metamorphic performance (Pechenik et al. 1998, Marshall et al. 2003). Thus, older larvae are viewed as being increasingly 'desperate' to settle regardless of settlement cues, a conceptual model known as the 'desperate larva hypothesis' (Toonen \& Pawlik 1994, 2001, Marshall \& Keough 2003). This hypothesis makes intuitive sense-the longer a larva remains in the plankton, the more costs or risks it accumulates.

However, despite its intuitive appeal, not all species exhibit decreasing selectivity. For example, some species will delay settlement in the absence of settlement cues for remarkably long periods of time (e.g. > $200 \mathrm{~d}$ in larvae of the sea hare Aplysia juliana, Kempf 1981). We summarized the available literature on the incidence of decreasing selectivity in marine invertebrate larvae in Table 1, and found that decreasing selectivity is indeed common among marine invertebrate larvae but that numerous exceptions occur. For reasons that will be made clear below, we include additional information on whether the larvae feed during the facultative planktonic phase and whether or not they can be classified as specialists or generalists. We classified species as 'specialists' if they had stringent habitat requirements at metamorphosis; usually, this requirement was a prey species upon which they fed.

Table 1. Summary of larval settlement behaviour for marine invertebrates in which the juvenile/adult stage has strict habitat requirements ('specialists') or can survive well in several different habitats ('generalists'). Species are grouped according to whether they can complete the larval period with or without larval feeding. See 'Introduction' for our definition of decreasing selectivity

\begin{tabular}{|c|c|c|c|}
\hline Species & $\begin{array}{c}\text { Larval } \\
\text { feeding }\end{array}$ & $\begin{array}{l}\text { Decreasing } \\
\text { specificity }\end{array}$ & Source \\
\hline \multicolumn{4}{|l|}{ Generalists } \\
\hline Haminaea callidegenita & No & $\checkmark$ & Gibson (1994) \\
\hline Bugula neritina & No & $\checkmark$ & Gribben et al. (2006) \\
\hline Watersipora subtorquata & No & $\checkmark$ & Gribben et al. (2006) \\
\hline Balanus amphitrite & No & $\checkmark$ & Miron et al. (2000), Thiyagarajan et al. (2002) \\
\hline Heliocidaris erythrogramma & No & $\checkmark$ & D. J. Marshall (unpubl. data) \\
\hline Holopneustes purpurescens & No & $\checkmark$ & R. Swanson (unpubl. data) \\
\hline Hydroides elegans & Yes & $\checkmark$ & Pechenik \& Qian (1998) \\
\hline Hermissenda crassicornis & Yes & $\checkmark$ & Avila (1998) \\
\hline Sabellaria alveolata & Yes & $\checkmark$ & Pawlik (1988) \\
\hline Strongylocentrotus droebachiensis & Yes & $\checkmark$ & Rumrill (1989) \\
\hline Phoronis psammophila & Yes & $\checkmark$ & Herrmann (1979) \\
\hline Phoronis muelleri & Yes & $\checkmark$ & Herrmann (1995) \\
\hline Crepidula plana & Yes & $\checkmark$ & Lima \& Pechenik (1985) \\
\hline Crepidula fornicata & Yes & $\checkmark$ & Pechenik (1984) \\
\hline \multicolumn{4}{|l|}{ Specialists } \\
\hline Pagurus hirsutiusculus & No & $\sqrt{ }$ & Harvey \& Colasurdo (1993) \\
\hline Pagurus granosimanus & No & $\checkmark$ & Harvey \& Colasurdo (1993) \\
\hline Berghia verrucicornis & No & $\checkmark$ & Carroll \& Kempf (1990) \\
\hline Phestilla sibogae & Yes $^{\mathrm{a}}$ & $x$ & Hadfield \& Pennington (1990) \\
\hline Aplysia juliana & Yes & $x$ & Kempf (1981) \\
\hline Adalaria proxima & Yes $^{\mathrm{a}}$ & $x$ & Lambert \& Todd (1994) \\
\hline Phoronis pallida & Yes & $x$ & Santagata (2004) \\
\hline Alderia modesta/sp. & Yes $^{\mathrm{a}}$ & $x^{b}$ & Krug (2001), Botello \& Krug (2006) \\
\hline
\end{tabular}


We classified species as 'generalists' if they could survive in a number of different habitats that were available to the settling larvae. We classified species as showing decreasing selectivity if they broadened the range of cues to which they responded as they aged, spontaneously metamorphosed (in the absence of any cues other than a microbial biofilm) as they aged or became indiscriminate with regard to known settlement cues. Although using the terms generalists and specialists is convenient for generalizations, it is worth noting that these are largely artificial terms-generalists and specialists represent extremes along a continuum of large and small differences in performance among habitats. Nevertheless, we are confident that species classified as generalists are more likely to survive in a wider range of habitats than those classified as specialists.

Why do some species show decreasing selectivity whereas others do not? Our efforts to answer this question may have been hampered by the fact that marine biologists have tended to overlook more general theoretical considerations of the issue. General models of habitat selection have demonstrated that decreasing selectivity is generally expected when the cost of searching (mortality, deferred search costs) is high and the relative benefit of settling in good vs. poor quality habitat is small (Ward 1987, Baker \& Rao 2004, Stamps et al. 2005). More recently, Stamps et al. (2005) suggested that the costs and benefits of remaining selective are mostly dependent on the availability of habitat, the proportion of habitat that is high quality, and the direct (e.g. mortality) or deferred costs of continuing to search for habitat. This would suggest that larval feeding whilst in the plankton or the depletion of energetic reserves would have limited effect on larval settlement behaviour. However, Marshall \& Keough (2003) found that larval energetic reserves strongly affected larval settlement behaviour in 3 species of colonial invertebrates with non-feeding larvae and, more recently, Botello \& Krug (2006) found that larval feeding strongly mitigated the onset of decreasing selectivity. We suspect that the discrepancy between current theory and empirical findings stems from the fact that, in several ways, marine larvae are very different to more general dispersing organisms in search of habitat. The costs of searching are relatively much higher for marine invertebrate larvae than for other searchers. Mortality in the plankton can be very high (Morgan 1995) and at rates that far exceed those considered in previous theoretical studies (Stamps et al. 2005). Furthermore, non-feeding larvae can deplete their resources such that survival and growth are greatly reduced within a few hours (Marshall et al. 2003). Understandably, this is a parameter space that more general models have not considered. Overall, there are
2 potential influences on decreasing selectivity for marine organisms with dispersive larvae: (1) the costs of settling in good vs. poor habitats and (2) energy intake during the facultative dispersal phase (feeding vs. non-feeding). Here we use a theoretical model to examine the effect of 2 life history characteristicswhether or not individuals feed during dispersal, and whether they are habitat specialists or generalists - on the adaptive value of decreasing selectivity. Based on these results, we generated predictions about what functional groups of species should exhibit decreasing selectivity. We then compared the general predictions of our model to the documented habitat search behaviour of marine invertebrates from a range of taxa. Marine invertebrates are an ideal group for examining such questions because of the enormous range of lifehistory strategies present in this group and the clear, natural dichotomies that exist in search costs and habitat requirements. Most marine invertebrates produce either feeding or non-feeding larvae, and the deferred search costs of the planktonic stage are clearly different for these 2 groups (Botello \& Krug 2006). In addition, some marine invertebrates have very stringent post-settlement requirements (i.e. a prey species) whereas others only require unoccupied space. We first overview the expression of these 2 life history characteristics in marine invertebrates and then introduce the theoretical model that we used to examine their influence on habitat selectivity.

\section{Feeding vs. non-feeding larvae}

Delaying metamorphosis can strongly reduce postmetamorphic performance in a range of marine invertebrates, because larval swimming can deplete energy reserves that would otherwise be used for postmetamorphic functions (Wendt 1998, 2000, Bennett \& Marshall 2005). Using the terminology of Stamps et al. (2005), energy allocated to swimming and searching for habitat constitutes a 'deferred' search cost because it reduces an individual's post settlement performance. However, in species with feeding larvae, extending the larval period does not necessarily result in reduced performance, presumably because energetic reserves are maintained by larval feeding (Pechenik \& Eyster 1989, Rumrill 1989). This has led to the suggestion that species with feeding larvae are more likely to exhibit delayed metamorphosis in the absence of an appropriate settlement cue and will not show decreasing selectivity (Pechenik 1990, Toonen \& Pawlik 2001). We examined whether there was a fitness benefit of decreasing selectivity for species that could feed in the plankton (i.e. counter the loss of energy reserves) vs. species that could not feed in the plankton. Some 
species have larval stages in which larval swimming is highly costly, whereas others have larval stages in which energetic reserves are depleted slowly (e.g. 10 vs. $0.36 \%$ of total reserves per hour in an ascidian and bryozoan larva, respectively; Bennett \& Marshall 2005). Thus, we explored the benefits of decreasing selectivity across a continuum of energy consumption rates (i.e. a range of deferred cost values) that are largely outside the parameter space previously explored in more general models.

\section{Generalists vs. specialists}

For marine invertebrates, several authors have used verbal arguments that species with stringent habitat requirements or species that can only occur in rare habitat should not exhibit decreased selectivity (Pechenik 1990, Harvey \& Colasurdo 1993). More recently, Botello \& Krug (2006) argued that the consequences of decreasing selectivity at settlement greatly differ between specialists and generalists. It is likely that for species that have stringent post-metamorphic habitat requirements (e.g. predators with specific prey, epibionts etc.), accepting a less preferred habitat would probably result in a much greater decrease in fitness relative to a species that just required unoccupied space. Thus, we compared the fitness benefits of decreasing selectivity when there were large (as for specialists) and small (as for generalists) differences in performance among preferred and non-preferred habitats. It is inevitable that when survival is only possible in preferred habitats, there will never be an advantage of decreasing selectivity, and when all habitats are of identical quality, decreasing selectivity will always be favoured. Thus our comparisons explored the consequences of decreasing selectivity within these extremes.

\section{MODEL}

We constructed a deterministic search model to compare the conditions under which decreasing selectivity should be favoured by a marine invertebrate whose larvae disperse in search of suitable habitat. We then varied deferred search costs (feeding vs. non-feeding) and the consequences of settlement choices (specialists vs. generalists). Our model is similar to that constructed by Stamps et al. (2005), but with several important differences. First, the deferred cost that we consider is a reduction in post-settlement survival. We use an empirically derived (e.g. Pechenik et al. 1996, Wendt 1998, Marshall et al. 2003) non-linear function to relate swimming costs to post-settlement survival. In contrast, Stamps et al. (2005) assumed that each time unit spent searching incurs 1 unit of deferred cost. Second, in Stamps et al.'s (2005) model, time is the currency used to link search period and deferred costs, as well as to constrain the maximum time available for search, whereas our model uses the energetic state of larvae. Our decision to focus on energy instead of time reflects the fact that, for marine larvae, energy can be better used to link the cost of searching to reduced post-settlement performance (Marshall et al. 2003). In addition, the maximum time available for marine larvae to search for habitat is unlikely to be constrained by external factors (that set a maximum time by which settlement must occur), and is more likely to be constrained by larval energy reserves.

We used a discrete time model with each time step set to $1 \mathrm{~d}$ of searching. We considered an environment that comprised suitable and non-suitable habitat. The probability of being in suitable habitat during a time step is proportional to its abundance. Similarly, a suitable habitat patch can be of either good or poor quality, and the probability of being good quality habitat is proportional to its abundance.

An individual's fitness $(w)$ is given by:

$$
w=\sum_{t=0}^{T} S_{g, t} w_{g}+S_{p, t} w_{p}
$$

where $S_{g, t}$ and $S_{p, t}$ are the proportion, of offspring that settle in good and poor quality habitat during each time step $t$, and $w_{g}$ and $w_{p}$ are the relative fitness values of an offspring settling in good and poor quality habitat, respectively. The proportion of individuals that settle in good and poor quality habitat during a time step is, respectively, given by:

$$
S_{g, t}=N_{t} E_{h} H_{g} A_{g, t} M_{g, x}
$$

and

$$
S_{p, t}=N_{t} E_{h}\left(1-H_{g}\right) A_{p, t} M_{p, x}
$$

where $N_{t}$ is the number of offspring searching for habitat, $E_{h}$ is the proportion of habitat in the environment, $H_{g}$ is the proportion of the habitat that is good quality, $A$ is the probability of an offspring accepting a habitat patch, and $M$ is the probability that the offspring survives after settling, which is dependent on habitat quality and the individual's energy level at settlement $(x)$.

$N_{t}$ decreases over time as a result of mortality during dispersal $(\mu)$ and individuals settling:

$$
N_{t+1}=\left(N_{t}-N_{t} \mu\right)\left[1-E_{h} H_{g} A_{g, t}-E_{h}\left(1-H_{g}\right) A_{p, t}\right]
$$

A constant mortality rate was applied for each day that the larvae spent dispersing in the plankton. We examined conditions where the mortality rate was high and low (Table 1). Estimates of mortality in the plankton vary, but our values are within the range of esti- 
mates and probably span the spectrum of mortality rates (Morgan 1995).

All offspring began the search period with the same amount of energy. During each time step spent searching, an individual's energy reserves decreased by a set amount (see 'Non-feeding vs. feeding' below and Table 2). A non-settled individual died once its energy reserves reached 0 . Therefore, the maximum number of time steps during which an individual could search was determined by its initial energy reserves and the rate of energy use during swimming.

The dispersal period of larvae is divided into 2 parts: an obligate dispersal period and a facultative dispersal period. During the obligatory dispersal period, larvae are physiologically incapable of metamorphosis and must remain in the plankton until they become competent to metamorphosise and settle. The duration of the obligatory dispersal period depends on a wide range of intrinsic (e.g. egg size) and extrinsic factors (e.g. temperature, food availability), all of which we keep constant. In our model, all larvae began dispersal with the same amount of energy and had to endure $3 \mathrm{~d}$ of obligate dispersal. During the obligate dispersal period, larvae consumed their energy reserves and suffered mortality (rates given in Table 2). It is important to note that because this obligate dispersal period was identical across our major parameter of interest (constant vs. decreasing selectivity), this period had no effect on the outcome of any part of our explorations.

Once larvae become competent to settle they enter a facultative dispersal phase. If habitat is encountered during facultative dispersal, the larvae must choose whether or not to settle based on the quality of the habitat. The probability that an offspring accepted a habitat patch and settled $(A)$ was modeled as either being constant or as decreasing over time (i.e. constant vs. decreasing selectivity). In runs where offspring had a constant acceptance value, the probability of an individual accepting a poor quality habitat was set at 0.3 , whereas the probability of accepting good quality habitat was 0.8. Sensitivity analyses showed that varying these values had little effect on the outcome of our model (Table 2). This is an important contrast to the model of Stamps et al. (2005): in our model, larvae could accept either habitat rather than accepting only Habitat A or B depending on whether searchers became indiscriminate or not. We believe this situation better reflects the fact that, in nature, larvae can settle in response to a range of cues but can 'prefer' some cues over others (Raimondi \& Keough 1990). However, it is worth noting that some species (e.g. Hydroides dianthus, Toonen \& Pawlik 2001) may genuinely exhibit dichotomous settlement behaviour, which is better reflected by the approach used by Stamps et al. (2005). Furthermore, unlike previous habitat search models, larvae were not assumed to always settle as soon as high quality habitat was encountered. This decision reflects empirical findings that a proportion of larvae do not immediately settle in high quality habitat when it is encountered (Marshall \& Keough 2003).

In runs where larvae exhibited decreasing selectivity, the probability that each habitat type would be accepted increased by a certain percentage (ranging from 1 to $20 \% \mathrm{~d}^{-1}$ ) at each time step. For example, after 3 time steps, a 'constant selectivity' larva would still have a $30 \%$ chance of accepting poor quality habitats but a 'decreasing selectivity' larva would have 33 to $100 \%$ chance (depending on the rate of decrease in selectivity) of accepting a poor quality habitat. Therefore, selectivity decreased linearly and by a conservative amount at each time step.

The probability that an offspring survives after settlement $(M)$ was modeled as a function of habitat quality and the offspring's remaining energy reserves. Post-settlement survival of larvae is strongly dependent on larval energy reserves in a range of marine invertebrates (Wendt 1998, Marshall et al.

Table 2. Range of parameter values used in the habitat search model and their effects on the adaptive advantage of decreased selectivity

\begin{tabular}{|c|c|c|}
\hline Parameter & Range & $\begin{array}{l}\text { Effect of increasing parameter } \\
\text { on decreased selectivity }\end{array}$ \\
\hline Instantaneous mortality rate $(\mu)$ & $0.1-0.5$ & $\uparrow$ benefit \\
\hline Probability of accepting good habitat $\left(A_{g}\right)$ & $0.1-0.99$ & $\downarrow$ benefit \\
\hline Probability of accepting poor habitat $\left(A_{p}\right)$ & $0.1-0.99$ & $\uparrow$ benefit \\
\hline Proportion of habitat in the environment $\left(E_{h}\right)$ & $0.1-0.9$ & $\downarrow$ benefit \\
\hline Proportion of the habitat that is good quality $\left(H_{g}\right)$ & $0.1-0.9$ & Non-linear: $\downarrow$ benefit at $H_{g}<0.3, \uparrow$ at $H_{g}>0.3$ \\
\hline Change in choosiness & $1-20 \%$ & No qualitative effect \\
\hline Rate of energy loss per time step $(\Delta x)$ & $0.001-20 \%$ & $\uparrow$ benefit \\
\hline Relative offspring fitness in poor quality habitat $\left(w_{p}\right)$ & $0.3-0.7$ & $\uparrow$ benefit \\
\hline
\end{tabular}


2003). The relationship between survival and energy reserves is typically sigmoidal: individuals with large energy reserves have a high probability of survival, whereas individuals with an energy level below a habitat-specific value have a much lower probability of survival (Marshall \& Keough 2004, Marshall et al. 2006). We modeled the sigmoidal relationship between energy level $(x)$ and probability of survival $(M)$ using the incomplete $\beta$ function, which is defined by the integral:

$$
M_{x}(x, \alpha, \beta)=\frac{B_{x}(\alpha, \beta)}{B(\alpha, \beta)}=\frac{1}{B(\alpha, \beta)} \int_{0}^{x} u^{\alpha-1}(1-u)^{\beta-1} d u
$$

where $\alpha$ and $\beta>0$, and $B(\alpha, \beta)$ is the value of the $\beta$ function:

$$
\frac{(\alpha-1) !(\beta-1) !}{(\alpha+\beta-1) !}
$$

The $\alpha$ and $\beta$ for poor quality habitat were chosen such that individuals with equivalent energy levels had a lower probability of surviving if they settled in poor compared to good quality habitat (Fig. 1). State-dependent reduction in post-settlement survival probability therefore corresponds to the deferred search costs examined by Baker \& Rao (2004) and Stamps et al. (2005).

Non-feeding vs. feeding. We used energy loss values that ranged from 0.001 to $20 \% \mathrm{~d}^{-1}$ (Table 2). At an energetic expenditure rate of $9 \%$, offspring could only search for habitat for $11 \mathrm{~d}$ before running out of energy, which represents a relatively long planktonic period for a non-feeding larva. Given that energy



Fig. 1. Fitness value of individual larvae settling in good (-) and poor quality habitats: small $(\cdots)$, intermediate $(--)$, and large (-..-) difference between good and poor habitat. On the $x$-axis, the energy level of offspring (which decreases over time) predicts relative fitness, and the quality of habitat into which larvae settle determines maximum fitness that can be achieved for a given energy level expenditure rates in non-feeding larvae can be much higher than $9 \% \mathrm{~d}^{-1}$ in nature (Bennett \& Marshall 2005), we could have modeled a higher rate; however, pilot explorations showed that $>9 \%$ invariably resulted in decreasing selectivity being favoured throughout our parameter space. We used $0.001 \%$ energy loss per day for feeding larvae, because most species with feeding larvae show only minor decreases in postmetamorphic performance when food is available (Pechenik \& Rice 2001).

Specialists vs. generalists. Data for survival in and out of preferred habitats reveal strong effects of habitat quality on subsequent performance in some species but not in others (Keough \& Downes 1982). To examine these 2 extremes, we varied the relative cost of settling in poor quality habitat by modifying both the probability of post-settlement survival and the relative fitness realized by offspring that settle in poor quality habitat. We compared 3 scenarios characterised by small, intermediate, or large differences between good and poor habitats (relative fitness $w_{p}$, Table 2 ; post-settlement survival, Fig. 1).

\section{RESULTS}

\section{Benefits of decreasing selectivity}

Our model predicted that decreasing selectivity would have greater fitness benefits than constant selectivity under most circumstances. When instantaneous search costs (planktonic mortality) were high, decreasing selectivity was always favoured over constant selectivity. Similarly, when suitable habitat abundance overall was very low, decreasing selectivity was always favoured because the chances of encountering habitat overall were so low that if any habitat were encountered, it should be accepted. When the probability of encountering good habitat is very low, the benefit of remaining selective is less than the direct and deferred costs suffered as a result of a longer search period. Conversely, when good quality habitat is very abundant, decreasing selectivity is favoured because less selective individuals are likely to settle by chance alone in good quality habitat, and do so more quickly such that lower deferred costs are incurred (Fig. 2, Table 2). Interestingly, changing the rate of decrease in selectivity had no qualitative effect on the benefits of decreasing selectivity: if decreasing selectivity carried a benefit at a low rate of decrease in selectivity, then it did at a higher rate also. However, the rate of decrease did affect the result quantitatively: if decreasing selectivity carried a benefit at a low rate of decrease in selectivity, then it carried an even larger benefit at a higher rate. 




Fig. 2. Relative fitness ( $\%$ of constant selectivity) of the decreasing selectivity phenotype in environments that vary in the proportion of good quality habitat; 4 combinations of habitat availability $\left(E_{h}\right)$ and energy expenditure rates $(\Delta x)$ are shown, and parameter values are presented as $\left(E_{h}, \Delta x\right)$ such that the top 2 lines represent conditions under which energetic costs of searching are high. Lines above $0 \%$ indicate a fitness benefit of decreasing selectivity, and those beneath $0 \%$ indicate a cost of decreasing selectivity such that constant selectivity would be favoured

\section{Feeding vs. non-feeding larvae}

Generally, increasing deferred costs (i.e. energy consumption rate) of searching reduced the benefits of decreasing selectivity (Fig. 3, Table 2). When the deferred costs of searching were high, decreasing selectivity was sometimes favoured, depending on the abundance of habitat and the relative abundance of good habitat (Fig. 2, Table 2). However, when deferred costs were extremely high (as would be expected for most non-feeding larvae), decreasing selectivity was always favoured.

\section{Generalists vs. specialists}

Abundance of habitat and quality differences between good and poor habitat were the most important factor in determining the relative benefits of decreasing selectivity. When there were only small differences in the fitness gains between habitats (as in the case of generalists), decreasing selectivity was always favoured. However, when there were medium to large differences in habitat quality and habitat was abundant overall (as is likely for specialists), constant selectivity was almost always favoured, regardless of whether good habitat was relatively abundant or not.

Whilst the benefits of decreasing selectivity depend on a range of factors (Table 2), some generalizations can be made regarding the influence of deferred search costs (larval feeding) and habitat quality effects. Feeding larvae that have stringent post-settlement requirements should never accept poor quality habitat unless mortality is very high, and non-feeding larvae with high energy use rates in the plankton should always become less choosy if they survive reasonably well in a range of habitats. It is important to note that these factors merely increase or decrease the relative benefits of decreasing selectivity; they are not absolute measures of which strategy selection should favour.

\section{Variations on the theme}

For the sake of generality and simplicity, we kept mortality/energy use in the plankton and habitat quality constant over time. In reality, each of these factors is likely to change during the larval period. For example, habitats that appear to be good quality at settlement may later deteriorate and vice versa (Raimondi \& Keough 1990). We examined the effects of variation in each of these parameters on the benefits of decreasing selectivity.

Mortality/energy use. Whilst increases in the mortality rate increase the benefit of decreasing selectivity, random variation about the mean has no effect. However, if larval energy state during the facultative dispersal stage affects the mortality rate (for example

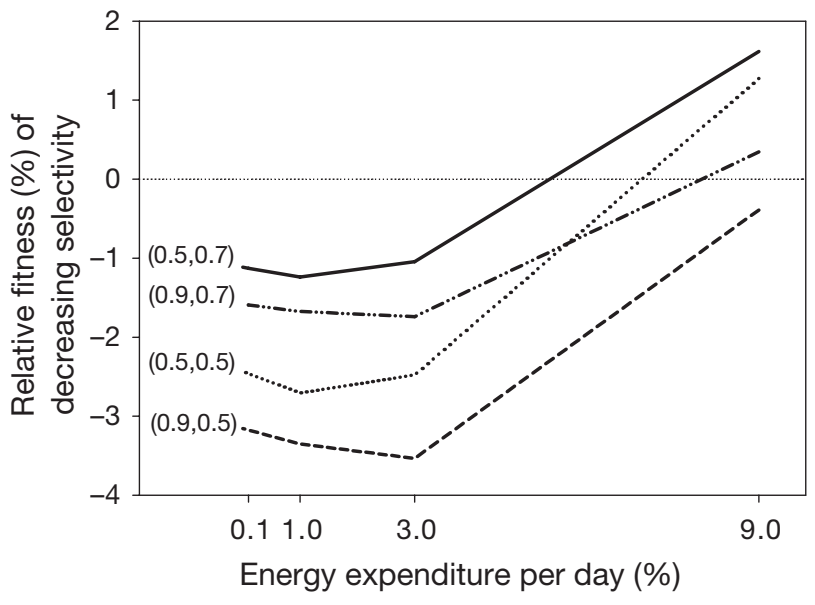

Fig. 3. Relative fitness ( $\%$ of constant selectivity) of the decreasing selectivity phenotype under conditions where the energetic cost of searching differ; 4 environments that vary in relative area of available habitat $\left(E_{h}\right)$ and proportion of good quality habitat $\left(H_{g}\right)$ are shown, and parameter values are presented as $\left(E_{h}, H_{g}\right)$. Lines above $0 \%$ indicate a fitness benefit of decreasing selectivity, and those beneath $0 \%$ indicate a cost of decreasing selectivity such that constant selectivity would be favoured 
if larval swimming speed was related to energy reserves), then the benefits of decreasing selectivity are further increased because this will result in a higher direct cost of searching for habitat overall. Similarly, if energy use were to increase over time, then this would further raise the benefit of decreased selectivity due to the higher indirect cost of searching. Basically, our explorations suggest that anything that raises the costs of the searching phase (i.e. changes in energy use or mortality rate) over time raises the benefits of decreasing selectivity. The converse is true for decreases in costs.

Facultative feeding. Larval feeding during the facultative stage may increase larval energetic reserves and thus decreasing selectivity would only be favoured when planktonic mortality rates were very high, outweighing the benefits of increased post-metamorphic performance.

Habitat quality. Increasing the chance that a habitat will change in quality (i.e. making habitat quality variable over time) increases the benefits of decreasing selectivity. This is because good habitats that 'switch' to bad habitats and vice versa effectively result in a smaller average difference in the performance of larvae that select good vs. bad habitats.

\section{DISCUSSION}

Decreasing selectivity appeared to be favoured by selection across the majority of the parameter space explored in our model: as searchers age, accumulate deferred costs and risk mortality, they should become less choosy with regard to colonization cues. Thus our model supports the general finding in marine invertebrates that searching larvae exhibit decreased selectivity over time. However, our model also predicts that there should be exceptions to the 'rule' of decreasing selectivity, which also conforms with the available literature (Toonen \& Pawlik 2001). When deferred costs are very high, decreasing selectivity is always favoured; however, when these costs are lower, the benefits of decreasing selectivity are dependent on the difference in habitat quality. Thus, for marine invertebrates, non-feeding larvae with high energetic costs (e.g. ascidian larvae, Bennett \& Marshall 2005) should always exhibit decreasing selectivity; in contrast, for feeding larvae, the benefits of decreasing selectivity depend on whether they are specialists or generalists.

Is there any support for our predictions regarding which functional groups should or should not exhibit decreasing selectivity? Going back to the available literature on marine invertebrates (Table 1), our findings agreed well with the predictions of our model. Within the specialists, none of the species with feeding larvae (i.e. when deferred costs are low) exhibited decreasing selectivity, whereas all 9 species with non-feeding larvae (when deferred costs are higher) showed decreasing selectivity (Table 1). We note that Hydroides dianthus appears to be an exception to the studies shown in Table 1 ; it is probably a generalist, but most larvae in this species never become less discriminating in their settlement requirements, even in the absence of food (Toonen \& Pawlik 2001). We cannot account for why this species - which appears capable of surviving on unoccupied space-remains so selective whilst incurring direct and deferred costs, but look forward to other theoretical considerations of the issue (Toonen \& Tyre in press).

\section{Comparisons with other models}

Our findings contrast with more general models in some important ways. Stamps et al. $(2005$, p. 515) concluded that costs during searching are of limited importance relative to other parameters such as habitat availability, but we found that when search costs (mortality in the plankton and/or deferred costs) were high, decreasing selectivity was almost always favoured, regardless of habitat availability. This difference in findings probably stems from a number of factors. First, our approaches were slightly different in the fact that our searching larvae could accept multiple habitats simultaneously from the outset (cf. Stamps et al. [2005], where searchers must 'switch' to accepting both), and we did not set a finite time horizon for larvae to search per se; rather, we gave larvae a finite amount of energy that they could use. Second and probably more importantly, we explored a parameter space that was not examined by Stamps et al. (2005), which included much higher rates of mortality in the plankton and higher deferred costs. Whilst ecologically relevant to marine organisms with planktonic larvae, neither the high rates of mortality nor the deferred costs are likely to occur in other organisms, and so it is perhaps unsurprising that the more general model of Stamps et al. (2005) found that habitat availability was more important.

Although our model was specifically developed for marine invertebrates, we suggest that it has broader implications for terrestrial systems. For example, in some phytophageous insects, searching individuals also become more desperate as they age. Ovipositing mothers decrease their selectivity and accept lowerranked host plants as they age or their egg load increases (Courtney et al. 1989). This conceptual model is known as the hierarchy-threshold model, but is remarkably similar to the desperate larva hypothesis. Different species vary widely in the number of plant or insect hosts that they can lay their eggs upon: 
some are specialists that can utilize only a single host, whereas others can use multiple hosts. Whilst we did not compile any literature on decreasing selectivity in generalist and specialist insects, our model would predict that decreasing specificity is more likely in generalists than specialists and we await further data to test this prediction. Decreased selectivity as a function of age or time spent searching has been found to occur during mate choice (Moore \& Moore 2001), and we would predict that when there is high variation in male mate quality, females will remain selective or choosy for longer.

We did not include the effects of intraspecific competition in our model because we would need to include a game theoretic modeling approach with our current time step model, resulting in an ungainly and intractable model. However, we suspect that postsettlement density dependence would introduce another deferred cost of searching and increase the advantages of decreasing selectivity. If competition increases during the search period, then the absolute quality of the habitat located and the fitness benefits accrued by individuals that spend a longer time searching will be decreased. In addition, if the distribution of settling individuals approximates the ideal free distribution (Fretwell \& Lucas 1970), then the relative benefit of settling in good compared with poor quality habitat will decrease during the search period, further decreasing the benefits of remaining selective. Thus, although we did not formally include density dependence in our model, we predict that decreasing selectivity will be more common in species such as barnacles, for which intraspecific competition can be intense (Connell 1961). Presumably, competition will increase throughout a settlement season and, interestingly, Jarrett (1997) found that barnacle cyprids became less choosy with regard to settlement surfaces as the season progressed, which would support our predictions.

Our model has clear predictions for the role of deferred costs (larval energy use) in determining the benefits of decreasing selectivity among species. Species with non-feeding larvae are predicted to achieve greater fitness gains from decreasing selectivity than species with feeding larvae. Interestingly, our model also predicts that species for which there are strong benefits of decreasing selectivity (e.g. non-feeding larvae that burn their energy reserves quickly) should become indiscriminate much faster than species for which there are only weak benefits of decreasing selectivity. This may explain why some species become indiscriminate almost immediately whereas others can take longer.

Given the influence of deferred costs on the benefits of decreasing selectivity, it is interesting that some marine invertebrates that are specialists are also facultative feeders as searching larvae (i.e. larval feeding is not crucial for development, but can occur). By supplementing their energetic reserves with planktonic feeding when appropriate habitat is absent, it may be that facultative planktotrophs can better 'afford' to be specialists than species with non-feeding larvae. Our model would predict that species with non-feeding larvae are less likely to be specialists because this larval type essentially constrains selectivity.

\section{Intraspecific implications}

Our model also has some interesting predictions for the role of deferred costs within species. Most current models of larval settlement treat larvae as a homogenous population that does not change settlement preferences (reviewed by Raimondi \& Keough 1990). Our model predicts that larval settlement preferences should be surprisingly dynamic. Within planktotrophic species, deferred costs are low when planktonic food is abundant, but deferred costs are higher when food is scarce (Pechenik 1990, Pechenik et al. 1996, Qian \& Pechenik 1998, Pechenik \& Rice 2001). Thus, we might expect that within planktotrophs, larvae will show different levels of decreasing selectivity according to local food conditions. There appears to be strong support for this suggestion. Miron et al. (2000) found that larval exploratory behaviour is strongly related to energetic reserves (a product of larval feeding) in barnacle larvae. More recently, Botello \& Krug (2006) found that non-fed larvae became more sensitive (required less of the specific cue to induce settlement) to settlement cues than fed larvae. Recently, it became apparent that there are strong effects of larval feeding on adult performance (Phillips 2004). Our results suggest that low planktonic food abundance may not only lead to settling larvae that have poor survival potential, but also to larvae that are more likely to settle in poor quality habitats.

Our model also makes some predictions regarding intraspecific variation for non-feeding larvae. Larger larvae start out with more energy reserves and so can better 'afford' to lose energy before post-metamorphic performance is negatively affected (i.e. the relative impact of deferred costs are lower in larger offspring). If larger larvae have more reserves overall, we might expect that they would be more likely to remain choosy for longer than smaller larvae because they begin life 'further' from the threshold that induces decreasing selectivity. However, we note that this may be countered somewhat by smaller larvae that use energy reserves more efficiently (e.g. Wendt 2000, Marshall \& Keough 2006); more data are needed to 
determine the relative costs of swimming for large and small larvae. Nevertheless, there is some evidence that larger larvae remaining choosier for longer: D. J. Marshall found that larger larvae remain choosy for longer in the absence of settlement cues and, in the field, larger offspring were more likely to settle in better quality habitat (Marshall \& Keough 2003). If true, this suggests that there is an added performance benefit of increased offspring size-a greater likelihood of settling in a high quality habitat.

Searchers should decrease their selectivity of settlement cues when there are significant costs associated with searching and the benefits of searching are small. We found that decreasing selectivity is favoured under most circumstances, which conforms well to the conceptual models discussed in the insect and marine invertebrate literature. However, we were also able to account for some of the exceptions to the rule and, for specialists with specific habitat requirements, found that constant selectivity should be favoured unless the deferred costs of searching are very large. Habitat choice for most organisms is clearly a dynamic process and apparent 'mistakes' may in fact be an adaptive strategy to avoid direct and deferred search costs in a range of organisms.

Acknowledgements. We thank Rob Toonen, Patrick Krug and 3 anonymous reviewers for excellent comments that greatly improved the manuscript. We also thank Roger Hughes for his very helpful editorial guidance throughout the review process. Discussions with Megan Huggett, Gimme Walter and Myron Zalucki helped to clarify our thoughts on the issue.

\section{LITERATURE CITED}

Avila C (1998) Competence and metamorphosis in the longterm planktotrophic larvae of the nudibranch mollusc Hermissenda crassicornis (Eschscholtz, 1831). J Exp Mar Biol Ecol 231:81-117

Baker MB, Rao S (2004) Incremental costs and benefits shape natal dispersal: theory and examples with Hemilepistus reaumuri. Ecology 85:1039-1051

Bennett CE, Marshall DJ (2005) The relative energetic costs of the larval period, larval swimming and metamorphosis for the ascidian Diplosoma listerianum. Mar Freshw Behav Physiol 38:21-29

Botello G, Krug PJ (2006) Desperate larvae revisited: age, energy and experience affect sensitivity to settlement cues in larvae of the gastropod Alderia sp. Mar Ecol Prog Ser 312:149-159

Carroll DJ, Kempf SC (1990) Laboratory of the aeolid nudibranch Berghia verrucicornis (Molussca: Opisthobranchia): some aspects off its development and life history. Biol Bull (Woods Hole) 19:143-253

Connell JH (1961) Effects of competition, predation by Thais lapillus, and other factors on natural populations of the barnacle Balanus balanoides. Ecol Monogr 31:61-104

Courtney SP, Chen GK, Gardner A (1989) A general-model for individual host selection. Oikos 55:55-65

Fretwell SC, Lucas HL Jr (1970) On territorial behavior and other factors influencing habitat distribution in birds. I. Theoretical development. Acta Biotheoretica 19:16-36
Gibson G (1994) Why be choosy_temporal changes in larval sensitivity to several naturally occurring metamorphic inducers in the opisthobranch Haminaea callidegenita. J Exp Mar Biol Ecol 194:9-24

Gribben PE, Marshall DJ, Steinberg PD (2006) Less inhibited with age? Larval age modifies responses to natural settlement inhibitors. Biofouling 22:101-106

Hadfield MG, Pennington JT (1990) Nature of the metamorphic signal and its transduction in larvae of the nudibranch Phestilla sibogae. Bull Mar Sci 46:455-464

Harvey AW, Colasurdo EA (1993) Effects of shell and food availability on metamorphosis in the hermit crabs Pagurus hirsutiusculus (Dana) and Pagurus granosimanus (Stimpson). J Exp Mar Biol Ecol 165:237-249

Hentschel BT, Emlet RB (2000) Metamorphosis of barnacle nauplii: effects of food variability and a comparison with amphibian models. Ecology 81:3495-3508

Herrmann K (1979) Larval development and metamorphosis of Phoronis psammophila (Phoronida. Tentaculata). Helgol Wiss Meeresunters 32:550-581

Herrmann K (1995) Induction and regulation of metamorphosis in planktonic larvae: Phoronis muelleri (Tentaculata) as archetype. Helgol Meeresunters 49:255-281

Jarrett JN (1997) Temporal variation in substrate specificity of Semibalanus balanoies (Linnaeus) cyprids. J Exp Mar Biol Ecol 211:103-114

Jarrett JN, Pechenik JA (1997) Temporal variation in cyprid quality and juvenile growth capacity for an intertidal barnacle. Ecology 78:1262-1265

Kempf SC (1981) Long lived larvae of the gastropod Aplysia juliana: do they disperse and metamorphose or just slowly fade away? Mar Ecol Prog Ser 6:61-65

Keough MJ, Downes BJ (1982) Recruitment of marine invertebrates: the role of active larval choices and early mortality. Oecologia 54:348-352

Knight-Jones EW (1951) Gregariousness and some other aspects of the settling behaviour of Spirobis. J Mar Biol Assoc UK 30:201-222

Knight-Jones EW (1953) Laboratory experiments on gregariousness during settling in Balanus balanoides and other Barnacles. J Exp Biol 30:584-599

Krug PJ (2001) Bet-hedging dispersal strategy of a specialist marine herbivore: a settlement dimorphism among sibling larvae of Alderia modesta. Mar Ecol Prog Ser 213: $177-192$

Lambert WJ, Todd CD (1994) Evidence for a water-borne cue inducing metamorphosis in the dorid nudibranch mollusk Adalaria proxima (Gastropoda, Nudibranchia). Mar Biol 120:265-271

Levitan DR (2000) Optimal egg size in marine invertebrates: theory and phylogenetic analysis of the critical relationship between egg size and development time in echinoids. Am Nat 156:175-192

Lima GM, Pechenik JA (1985) The influence of temperature on growth rate and length of larval life of the gastropod, Crepidula plana Say. J Exp Mar Biol Ecol 90:55-71

Marshall DJ, Keough MJ (2003) Variation in the dispersal potential of non-feeding invertebrate larvae: the desperate larva hypothesis and larval size. Mar Ecol Prog Ser 255:145-153

Marshall DJ, Keough MJ (2004) When the going gets rough: effect of maternal size manipulation on offspring quality. Mar Ecol Prog Ser 272:301-305

Marshall DJ, Keough MJ (2006) Complex life-cycles and maternal provisioning in marine invertebrates. Integr Comp Biol 46:643-651

Marshall DJ, Pechenik JA, Keough MJ (2003) Larval activity 
levels and delayed metamorphosis affect post-larval performance in the colonial, ascidian Diplosoma listerianum. Mar Ecol Prog Ser 246:153-162

Marshall DJ, Cook CN, Emlet RB (2006) Offspring size effects mediate competitive interactions in a colonial marine invertebrate. Ecology 87:214-225

Miron G, Walters LJ, Tremblay R, Bourget E (2000) Physiological condition and barnacle larval behavior: a preliminary look at the relationship between TAG/DNA ratio and larval substratum exploration in Balanus amphitrite. Mar Ecol Prog Ser 198:303-310

Moore PJ, Moore AJ (2001) Reproductive aging and mating: the ticking of the biological clock in female cockroaches. Proc Natl Acad Sci USA 98:9171-9176

Morgan SG (1995) Life and death in the plankton: larval mortality and adaptation. In: McEdward L (ed) Ecology of marine invertebrate larvae, Vol 1. CRC Press, Boca Raton, FL, p 279-322

Pawlik JR (1988) Larval settlement and metamorphosis of two gregarious sabellariid polychaetes: Sabellaria alveolata compared with Phragmatopoma californica. J Mar Biol Assoc UK 68:101-124

Pechenik JA (1984) The relationship between temperature, growth rate, and duration of planktonic life for larvae of the gastropod Crepidula fornicata (L.). J Exp Mar Biol Ecol 74:241-257

Pechenik JA (1990) Delayed metamorphosis by larvae of benthic marine-invertebrates: Does it occur? Is there a price to pay? Ophelia 32:63-94

Pechenik JA, Eyster LS (1989) Influence of delayed metamorphosis on the growth and metabolism of young Crepidula fornicata (Gastropoda) juveniles. Biol Bull (Woods Hole) 176:14-24

Pechenik JA, Qian PY (1998) Onset and maintenance of metamorphic competence in the marine polychaete Hydroides elegans Haswell in response to three chemical cues. J Exp Mar Biol Ecol 226:51-74

Pechenik JA, Rice ME (2001) Influence of delayed metamorphosis on postsettlement survival and growth in the sipunculan Apionsoma misakianum. Invertebr Biol 120: 50-57

Pechenik JA, Hammer K, Weise C (1996) The effect of starvation on aquisition of competence and post-metamorphic performance in the marine prosobranch gastropod Crepidula fornicata. J Exp Mar Biol Ecol 199: $137-152$

Editorial responsibility: Roger Hughes (Contributing Editor), Bangor, UK
Pechenik JA, Wendt DE, Jarrett JN (1998) Metamorphosis is not a new beginning. Bioscience 48:901-910

Phillips NE (2004) Variable timing of larval food has consequences for early juvenile performance in a marine mussel. Ecology 85:2341-2346

Qian PY, Pechenik JA (1998) Effects of larval starvation and delayed metamorphosis on juvenile survival and growth of the tube-dwelling polychaete Hydroides elegans (Haswell). J Exp Mar Biol Ecol 227:169-185

Raimondi PT, Keough MJ (1990) Behavioural variability in marine larvae. Aust J Ecol 15:427-437

Rumrill SG (1989) Substratum selectivity, post-larval growth, and survival following extended competence in Strongylocentrotus droebachiensis. Am Zool 29:29A

Santagata S (2004) A waterborne behavioral cue for the Actintroch larva of Phoronis pallida (Phoronida) produced by Upogebia pugettensis (Decapoda: Thalassinidea). Biol Bull (Woods Hole) 207:103-115

Stamps JA, Krishnan VV, Reid ML (2005) Search costs and habitat selection by dispersers. Ecology 86:510-518

Thiyagarajan V, Harder T, Qian PY (2002) Relationship between cyprid energy reserves and metamorphosis in the barnacle Balanus amphitrite Darwin (Cirripedia; Thoracica). J Exp Mar Biol Ecol 280:79-93

Toonen RJ, Pawlik JR (1994) Foundations of gregariousness. Nature 370:511-512

Toonen RJ, Pawlik JR (2001) Settlement of the gregarious tube worm Hydroides dianthus (Polychaeta: Serpulidae). II. Testing the desperate larva hypothesis. Mar Ecol Prog Ser 224:115-131

Toonen RJ, Tyre AJ (in press) If larvae were smart: simple model for optimal settlement behavior of competent larvae. Mar Ecol Prog Ser

Walters LJ, Miron G, Bourget E (1999) Endoscopic observations of invertebrate larval substrate exploration and settlement. Mar Ecol Prog Ser 182:95-108

Ward SA (1987) Optimal habitat selection in time limited dispersers. Am Nat 129:568-579

Wendt DE (1998) Effect of larval swimming duration on growth and reproduction of Bugula neritina (Bryozoa) under field conditions. Biol Bull (Woods Hole) 195:126-135

Wendt DE (2000) Energetics of larval swimming and metamorphosis in four species of Bugula (Bryozoa). Biol Bull (Woods Hole) 198:346-356

Wilson D (1953) The settlement of Ophelia bicornis Savigny larvae. J Mar Biol Assoc UK 32:209-233

Submitted: March 14, 2006; Accepted: September 26, 2006

Proofs received from author(s): April 5, 2007 